ORIGINAL ARTICLES

\title{
Role of carotid sinus syndrome and neurocardiogenic syncope in recurrent syncope and falls in patients referred to an outpatient clinic in a district general hospital
}

\author{
Abuzeid Eltrafi, Debra King, Joseph H Silas, Peter Currie, Michael Lye
}

\begin{abstract}
Carotid sinus syndrome (CSS) and neurocardiogenic syncope (NCS) are recognised as important causes of recurrent syncope and falls in the elderly. In this study the role of CSS (diagnosed with carotid sinus massage) and NCS (diagnosed with prolonged head-up tilt) in a district general hospital were investigated.

Over 27 consecutive months carotid sinus massage was performed in 139 patients. Of these $29(20.8 \%)$ patients (mean (SD) age of 78 (9) years) showed a positive response. Of these $18 \quad(62 \%)$ patients showed a positive response only when carotid sinus massage was performed with $70^{\circ}$ head-up tilt.

Thirteen $(8.7 \%)$ of the 149 patients who had prolonged head-up tilt testing were found to have NCS. The mean (SD) age for patients with NCS was 59 (26) years and the mean (SD) time required to produce a positive response during prolonged head-up tilt was 12 (5) minutes.

It is concluded that carotid sinus massage and head-up tilt testing are useful in patients presenting with unexplained syncope and falls in a district general hospital setting. Carotid sinus massage should be repeated upon head-up tilt if a negative response is obtained in the supine position.

(Postgrad Med F 2000;76:405-408)
\end{abstract}

Wirral Hospital

Merseyside, UK

Department of

Geriatric Medicine

A Eltrafi

D King

\section{Department of \\ Cardiology \\ $\mathrm{J}$ H Silas \\ P Currie}

University of

Liverpool, Merseyside, UK

M Lye

Correspondence to: Dr Abuzeid E Eltrafi, 65 Dickinson Court, Wakefield, West Yorkshire WF1 3TU, $\mathrm{UK}$

Submitted 28 April 1999 Accepted 22 November 1999
Keywords: syncope; carotid sinus syndrome; neurocardiogenic syncope

One of the most challenging and at times frustrating problems seen in clinical medicine is that of recurrent syncope and falls. These conditions are by nature episodic. Almost always the patients are examined after the event and many do not recall what happened. ${ }^{1}$ Despite these problems a diagnostic evaluation is essential because of the consequences of syncope and falls. Syncope may result in injuries, fractures, and even death. Recurrent syncope also prevents patients from driving. ${ }^{2}$ Carotid sinus syndrome (CSS) and neurocardiogenic syncope (NCS) have been increasingly recognised as important causes for syncope and falls.
Carotid sinus syndrome

Patients with CSS have exaggerated baroreflex (carotid sinus hypersensitivity), which in response to carotid sinus massage results in hypotension and/or bradycardia. The symptoms of CSS (unknown below the age of 50 years ${ }^{3}$ ) are precipitated by manoeuvres which cause mechanical stimulations of the carotid sinus (for example, head turning in the presence of tight neck wear and straining). Three subtypes of CSS are recognised: cardioinhibitory if carotid sinus massage produces asystole exceeding three seconds; vasodepressor if there is a fall in systolic pressure exceeding $50 \mathrm{~mm} \mathrm{Hg}$ in the absence of cardioinhibition; or a mixed subtype if both responses are present. ${ }^{3}$ Some authors still believe that CSS is a rare condition. Kapoor and colleagues reported CSS to be responsible for only one of 204 syncopal patients, ${ }^{4}$ while research centres report prevalence up to $45 \%$ attending a syncope clinic. ${ }^{5}$

\section{Neurocardiogenic syncope}

Head-up tilt testing has been used to provoke NCS. ${ }^{6}$ NCS is characterised by hypotension (fall in systolic pressure of $50 \mathrm{~mm} \mathrm{Hg}$ or more) and/or bradycardia (asystole of three seconds or more), induced by prolonged head-up tilt. Syncope is triggered by peripheral pooling of blood producing a low cardiac filling pressure. The low ventricular filling volume results in vigorous ventricular contractions which cause stimulation of a large number of mechanoreceptors thus provoking an increase in afferent neural output to the medulla. ${ }^{7}$ This increase in afferent output results in acute withdrawal of sympathetic activity to peripheral blood vessels and enhanced cardiac vagus activity producing hypotension and/or bradycardia (BezoldJarisch reflex), ${ }^{7}$ which produce the symptoms. ${ }^{8}$ NCS has a prevalence of $25 \%$ for patients seen in emergency room admissions with syncope ${ }^{9}$ and $11 \%$ for patients seen in a syncope clinic in a tertiary referral centre. ${ }^{10}$

The aim of this study was to answer the following question: how common were CSS and NCS in patients referred to the routine cardiology outpatient clinic of a district general hospital with unexplained syncope or falls?

\section{Methods}

The records were reviewed of patients referred to the cardiology clinics at Wirral Hospital for the period January 1996 to April 1998. This period was chosen because the protocol 
reported below was introduced in January 1996. Patients had been referred to either a consultant cardiologist or a geriatrician with interest in cardiology. Details recorded included basic history, clinical examination, initial postural blood pressure measurement, and initial investigations (including electrocardiography and echocardiography). All patients whose symptoms remained unexplained after the above underwent carotid sinus massage and head-up tilt tests. Patients who had carotid bruit, myocardial infarction, or cerebrovascular accidents in the previous three months were not referred for investigation. A doctor and cardiac technician performed the tests.

PROTOCOL

The patient rested supine for five minutes while blood pressure was monitored using the Finapres (Ohmeda, Englewood, CO, USA). While the patient was supine carotid sinus massage was performed-first on the right for five seconds and after one minute repeated on the left. If that was negative the patient was tilted on electrically driven table with footboard to $70^{\circ}$ and carotid sinus massage was repeated after two minutes as before. Finally the patient remains tilted for 45 minutes and the blood pressure and the heart rate are recorded continuously. The test was terminated as soon as a positive response was obtained. Patients below the age of 50 years were not investigated for CSS (see discussion).

DATA ANALYSIS

Student's $t$ test was used for comparison between different groups. Data were expressed as a mean (SD) and statistical significance was set at $\mathrm{p}<0.05$.

\section{Results}

CAROTID SINUS SYNDROME

During the 27 month period 139 patients (82 females, 57 males) were investigated for CSS. The age range of the patients was 51-91 years with a mean of 74 (11) years. Of the 139 patients who had carotid sinus massage 29 (20.8\%) showed a positive response. Eighteen patients of these ( $62 \%$ of 29 patients) were positive only when carotid sinus massage was done after the head-up tilt test. The majority of patients with a positive response were of a vasodepressor CSS subtype (table 1). The mean time for asystole for the patients who showed a cardioinhibitory response was $5.0(0.8)$ seconds.

The mean age of patients with a positive response was 78 (9) years. Patients who showed a vasodepressor CSS were significantly older than those with cardioinhibitory or mixed CSS (table 1). The 110 patients who had a negative

Table 1 Characteristics of patients with CSS

\begin{tabular}{llll}
\hline Subtype of CSS & Male & Female & $\begin{array}{l}\text { Mean (SD) } \\
\text { age (years) }\end{array}$ \\
\hline (A) Vasodepressor & 6 & 10 & $82(7)$ \\
(B) Cardioinhibitory & 3 & 5 & $77(8)^{\star}$ \\
(C) Mixed & 2 & 3 & $71(7) \dagger \ddagger$ \\
\hline
\end{tabular}

${ }^{\star} \mathrm{p}<0.001$, comparison of the age between (A) and (B); $t \mathrm{p}<0.05$, comparison of the age between $(\mathrm{A})$ and $(\mathrm{C}) ; \neq \mathrm{p}>0.05$ comparison of the age between (B) and (C).
Table 2 Age and sex of the patients with NCS

\begin{tabular}{llll}
\hline Groups & Male & Female & $\begin{array}{l}\text { Mean }(S D) \\
\text { age }(\text { years })\end{array}$ \\
\hline Young & 1 & 3 & $25(13)$ \\
Old & 3 & 6 & $67(8)^{\star}$ \\
\hline
\end{tabular}

$\mathrm{p}<0.05$, comparison of age between the two groups.

response to carotid sinus massage 48 (43.6\%) were females and the mean age for all who showed a negative response was 73 (11) years. There were no complications from carotid sinus massage in any of the patients tested. Of the eight patients who showed cardioinhibitory CSS four were treated with permanent pacemakers, in three it was decided to reassess their symptoms over a longer period, and one refused permanent pacemaker insertion. All patients with positive response were advised (appendix 1) to avoid situations likely to worsen their symptoms.

\section{NEUROCARDIOGENIC SYNCOPE}

During the 27 months 149 patients had head-up tilt tests for a maximum of 45 minutes to investigate NCS. Of these $90(60.2 \%)$ were females. The age range for the patients tested for NCS was 15-83 years with a mean age of 66 (20) years. The head-up test was positive in 13 $(8.7 \%)$ patients of whom nine $(69.2 \%)$ were females. The mean age for all patients who had a positive test was 59 (26) years. It was noted that there were two peaks for the age of the patients who had NCS (table 2): a young age group (four patients) with a mean age of 25 (13) years and an older group (nine patients) with a mean age of 67 (8) years. The mean reduction in systolic blood pressure in patients who showed vasodepression was 77 (26) $\mathrm{mm}$ $\mathrm{Hg}$.

Although the maximum time for the head-up tilt test was 45 minutes, it was noted that the mean time for a positive response was only 12 (5) minutes with a range of 5-18 minutes. Twelve patients with a positive response to prolonged head-up tilt testing showed a vasodepressor response and only one patient showed a mixed response.

All the patients with NCS were treated conservatively (two patients were treated with fludrocortisone but the majority were advised on ways to prevent their symptoms; appendix 1).

\section{Discussion}

Syncope and falls may be devastating for patients, their relatives, and carers and also drain the resources of the National Health Service. For example fractured femurs cost about $£ 165$ million a year and $20 \%$ of orthopaedic beds are occupied by these patients ${ }^{11}$ with a mortality of $30 \%-40 \%$ and a substantial disability among survivors. ${ }^{12}$ It is therefore essential to identify causes of recurrent syncope and falls, in order to select treatment and prevent the associate morbidity and mortality.

ROLE OF CSS IN RECURRENT SYNCOPE AND FALLS This retrospective study suggests that CSS is responsible for recurrent falls and syncope in $20.8 \%$ of patients referred to a medical 
outpatient clinic. This is not as high as that reported in tertiary or research centres ${ }^{5}$ but is higher than other reports. ${ }^{4}$ The reason for this difference is not clear. Our finding that patients with CSS are old is similar to other reports. ${ }^{513}$ The association of CSS and age related cardiovascular disease (atheroma of the carotid sinus) may be a possible mechanism for $\mathrm{CSS}^{14}$ and explains the rarity of this syndrome in patients below the age of 50 years. ${ }^{10}$

Although 13 patients showed significant cardioinhibition (five of these also had hypotension), only four patients were referred for permanent pacemakers. Sequential pacing is regarded by most as the treatment of choice as it has been shown to abolish syncope in $85 \%$ $90 \%$ of patients ${ }^{15}$ but the treatment should be tailored to the individual patient and their needs (for example the need to drive).

The treatment of patients with vasodepressor CSS is still controversial. Although there are reports that fludrocortisone is beneficial, ${ }^{16}$ it is not routinely used. The present advice is to avoid situations that lead to stimulation of the carotid sinuses, such as swift head turning in the presence of tight neckwear, straining, or prolonged standing.

This report showed there were no complications from carotid sinus massage in the supine position or after the head-up tilt test, although cardiac and neurological complications have been reported. ${ }^{17}{ }^{18}$ Cardiac complications generally occur in patients with underlying acute cardiac condition undergoing therapeutic rather than diagnostic massage ${ }^{18}$ and residual neurological deficits are very rare $(0.14 \%)$ if the duration of the carotid sinus massage and the contraindication to the test described above are followed. ${ }^{17}$

ROLE OF NCS IN RECURRENT SYNCOPE AND FALLS NCS was diagnosed in $8.7 \%$ of patients who had a prolonged head-up tilt test. This is comparable to the findings in the prospective study of McIntosh and colleagues ${ }^{10}$ and similar to that reported recently from a district general hospital. ${ }^{19}$ However, Fitzpatrick and Sutton reported NCS to be responsible for up to $74 \%$ of patients with similar symptoms. ${ }^{20}$ This large prevalence ${ }^{20}$ may be explained by the inclusion in the definition of NCS of patients who showed not only asystole but also those who had bradycardia (pulse $<60$ beats/min) only during the head-up tilt test.

In the present study the mean time to NCS after the head-up tilt test was noted to be 12 (5) minutes. This finding in addition to that of Fitzpatrick and Sutton who reported a mean time of 25 minutes (range 15-35) ) $^{20}$ and that of McIntosh and colleagues who reported a mean time of 24 (6) minutes ${ }^{10}$ perhaps suggests that the head-up tilt test could be limited to 35 minutes, which makes the procedure more acceptable.

The significance of the observation in this study that the age of the patients who had NCS was in two peaks, young and old, is not clear. The number of the patients in this study is small to draw any conclusion; however, previous reports suggest that the pattern of NCS in the young and old is different. ${ }^{8}$ The young were observed to develop the syncope abruptly during the head-up tilt test with classical symptoms of vasovagal attack whereas the drop in the blood pressure and the symptoms were more gradual in older people. The reason for these differences is not known as it has been reported that healthy ageing has no quantitative and minimal qualitative effects upon the haemodynamic responses to the head-up tilt test. $^{21}$

Some centres used intravenous isoprenaline infusion during the head-up tilt test to increase the sensitivity of the test ${ }^{8}$; however as this has been reported to alter the specificity of the test $\mathrm{t}^{22}$ this method was avoided.

Treatment of NCS varies between centres. Disopyramide with its negative inotropic and anticholinergic effects was reported to prevent tilt induced syncope ${ }^{23}$, and $\beta_{1}$-adrenergic blocking agents that diminish the force of ventricular contractions, have been reported to be useful. ${ }^{24}$ Hydrocortisone by increasing the blood volume was claimed to benefit the hypotension of NCS. ${ }^{25}$ Recently midodrine (a specific $\alpha$-adrenergic agonist) and serotonin reuptake inhibitors fluoxetine and sertraline hydrochloride were also reported to be helpful. ${ }^{26-28}$ This variable approach to the treatment of NCS illustrates the difficulties in the management of this condition. In patients whose syncope occurs only occasionally, education and advice about the nature of their condition and avoidance of the factors that trigger it may be adequate. In patients who have severe and frequent attacks of NCS drug treatment should be tried and in those who have significant cardioinhibition and fail to response to drug therapy permanent pacing can be useful. ${ }^{29}$

\section{Conclusion}

This study confirms the usefulness of carotid sinus massage and the head-up tilt test in a district general hospital for investigation of patients who had unexplained syncope and falls. It also illustrates that a large percentage of CSS will remain undiagnosed if carotid sinus massage is confined to the supine position as still practised in many hospitals.

We would like to thank Mr J Verdin, Miss K Collins, Miss $\mathrm{K}$ Meckell, and all the staff in the Cardiology and the Medical Records departments at Arrowe Park Hospital for the help and Records departments at Arrowe Park Hospital for the help and
support to produce this study. Finally we also thank Miss D support to produce this study. Finally
Devine for preparing the manuscript.

\section{Appendix 1}

Advice to patients with faints and blackouts (patients with CSS, NCS, or postural hypotension):

1. Blood pressure tends to be lowest in the morning and symptoms are likely to be worse then, so take particular care at this time of the day.

2. Get out of bed in stages:

(A) Perform calf flexion, leg and arm exercises before sitting up in bed (prevents pooling of blood).

(B) Come to a sitting position very slowly. If dizziness occurs lie down and start bed exercises again. 
(C) After sitting on the side of the bed without dizziness slowly come to a standing position.

3. Avoid prolonged sitting. Practice crossing and uncrossing legs before standing.

4. Wear high leg support tights during the day. Remove them at night.

5. Avoid bending and stooping followed by sudden righting. Pause between postural changes (slowing postural changes helps to decrease symptoms).

6. Drink coffee or strong tea as caffeine helps to prevent low blood pressure, but no more than five cups a day.

7. Drink plenty of fluids, ideally 1-2 litres a day.

8. Raise the head of the bed (that is with blocks to $10^{\circ}$ ).

9. Avoid large meals (eat small meals often).

10. Avoid alcohol (this will exacerbate symptoms).

11. Avoid standing for long periods (for example in church.).

1 Kenny RA, Traynor G. Carotid sinus syndrome-clinical characteristics in elderly patients. Age Ageing 1991;20:44954

2 Decter BM, Goldner B, Cohen TJ. Vasovagal syncope as a cause of motor vehicle accidents. Am Heart $\mathcal{F} 1994 ; 127$ 1619-21.

3 Walter PF, Crawley IS, Dorney ER. Carotid sinus hypersensitivity and syncope. Am $\mathcal{F}$ Cardiol 1978;42:396-403.

4 Kapoor WN, Karpf M, Wieand S, et al. A prospective evaluation and follow-up of patients with syncope. $N$ Engl $F \mathrm{Med}$ 1983;309:197-204.

5 McIntosh S, da Costa D, Kenny RA. Benefits of an integrated approach to the investigation of dizziness, falls and syncope in elderly patients referred to a syncope clinic. Age Ageing 1993;22:53-8.

6 Kenny RA, Ingram A, Bayliss J, et al. Head-up tilt: a useful test for investigating unexplained syncope. Lancet 1986;i: test for

7 Mark AL. The Bezold-Jarish reflex revisited: clinical implications of inhibitory reflexes originating in the heart. $\mathcal{F}$ Amplications of inhibitory

8 Grubb BP, Kosinski D. Current trends in aetiology, diagnosis and management of neurocardiogenic syncope. Cur Opin Cardiol 1996;11:32-41.
9 Weissler AM, Warren JV. Syncope: pathophysiology and differential diagnosis. In: Hurst JW, Logue RB, Rackley CE, et $a l$, eds. The heart. New York: McGraw Hill, 1986: 507-29.

10 McIntosh S, da Costa D, Kenny RA. Outcome of an integrated approach to the investigation of dizziness, falls and syncope in elderly patients referred to a syncope clinic. Age Ageing 1993;22:53-8.

11 Lewis AF. Fractured neck of femur. Changing incidence. BMF 1981;283:1217-20.

2 Keene GS, Parker M J, Pryor GA. Mortality and morbidity after hip fractures. BMF 1993;307:1248-50.

13 Strasberg B, Sagie A, Erdman S, et al. Carotid sinus hypersensitivity and the carotid sinus syndrome. Prog Cardiovasc Dis 1989;31:379-91.

14 Solmon S. The carotid sinus syndrome. Am f Cardiol 1958; 2:345-50.

15 Bringole M, Menozzi C, Lilli G, et al. Long term outcome of paced and non-paced patients with severe carotid sinus syndrome. Am ₹ Cardiol 1992;69:1039-43.

16 da Costa D, McIntosh S, Kenny RA. Benefits of fludrocortisone in the treatment of symptomatic vasodepressor tisone in the treatment of symptomatic vasodep
carotid sinus syndrome. Br Heart $\mathcal{7} 1993 ; 69: 308-10$.

17 Munro NC, McIntosh S, Lawson J, et al. Incidence of complications after carotid sinus massage in older patients with syncope. F Am Geriatr Soc 1994;42:1248-51.

18 Hilal H, Massumi R. Fatal ventricular fibrillation after carotid sinus stimulation. N Engl f Med 1966;275:157-8 .

19 Herd B, Gedge J. How to do it: cardiovascular investigation of falls and blackouts in a district general hospital. $C M E$ Bulletin Geriatric Medicine 1998;1:42-6.

20 Fitzpatrick A, Sutton R. Tilting towards a diagnosis in recurrent unexplained syncope. Lancet 1989;i:658-60.

21 Lye M, Walley T. Haemodynaemic responses in young and elderly, healthy subjects during ambient and warm head-up tilt. Clin Sci 1998;94:493-8.

22 McIntosh S, Lawson J, Kenny RA. Intravenous cannulation alters the specificity of head-up tilt testing for vasovagal syncope in elderly patients. Age Ageing 1994;71:317-19.

23 Milstein S, Buetikofer J, Dunningan A, et al. Usefulness of disopyramide for prevention of upright tilt induced disopyramide for prevention of upright tilt induced

24 Ferguson DW, Thomas MD, Mark AL. Effects of propranolol on reflex vascular responses to orthostatic stress in humans: role of baroreceptors. Circulation 1983;67:802-7.

25 Maloney JD, Jaeger FT, Fouad-Taazi FM, et al. Malignant vasovagal syncope: prolonged asystole provoked by head-up tilt. Cleve Clin F Med 1988;55:542-8.

26 Ward C, Kenny RA. Observation on midodrine in a case of vasodepressor neurogenic syncope. Clin Auton Res 1995;5: 257-60

27 Grubb BP, Wolfe DA, Samoil D, et al. Usefulness of fluoxetine hydrochloride for prevention of resistant upright tilt induced syncope. PACE 1993;16:458-64.

28 Grubb BP, Samoil D, Kosinki D, et al. Use of sertraline hydrochloride in the treatment of refractory neurocardiogenic syncope in children and adolescents. $₹ \mathrm{Am}$ Coll Cardiol genic syncope in

29 Ingram A, William T, Sutton R. Permanent pacing for cardioinhibitory malignant vasovagal syncope. Br Heart $\mathcal{f}$ 1994;71:274-81. 